\title{
Feasibility Study of Centralized Multi-agent Self-healing Power System with Superconducting Fault Current Limiter
}

\author{
Sujil A ${ }^{1} \cdot$ Saurabh Kumar Agarwal ${ }^{2} \cdot$ Rajesh Kumar $^{1}$
}

Received: 26 March 2015 / Accepted: 8 December 2015 / Published online: 4 February 2016

(C) Springer Science+Business Media Singapore 2016

\begin{abstract}
Recently, self-healing power systems have evolved towards centralized instructions and control functions. This paper delineates the feasibility analysis of self-healing power systems using Multi-Agent System (MAS) with Superconducting Fault Current Limiter (SFCL). For a complex power system included various microgrid, it is conceivably doubtful to expect that centralizing the aggregate system control function is practical. Hence, this paper is especially keen on settling on online decision by using smart microgrid control agents that collaborate during normal and fault situations. The control decision is taken by all agents which are deployed at different parts of the circuit. These agents collect their respective circuit information and send to the main central agent. Super conducting fault current limiter is an innovative electric equipment which has the ability to limit peak value of fault current within the first cycle of the fault current. However, a scarcity of research regarding the implementation of SFCL with the multi-agent system in a micro grid is felt. The centralized MAS with SFCL exposed in this paper help to support an enabling technology of future self-healing
\end{abstract}

Sujil A

sujilavijayan@gmail.com

Saurabh Kumar Agarwal

susasavy@gmail.com

Rajesh Kumar

rkumar.ee@gmail.com

1 Department of Electrical Engineering, MNIT Jaipur, Jaipur, Rajasthan, 302017, India

2 Department of Computer Engineering, MNIT Jaipur, Jaipur, Rajasthan, 302017, India power system. Feasibility analysis of the proposed centralized MAS with SFCL for self-healing power system has been done by considering faults in different locations of the grid.

Keywords Multi agent system $\cdot$ Superconducting fault current limiter $\cdot$ Self-healing power system $\cdot$ Smart grid . Centralized control

\section{Introduction}

Smart power system consists interconnection of large number of distributed generating stations like wind farms to the existing distribution network leads to the increment of fault current beyond the capacity of the conventional protection devices. The fault current having higher magnitude will damage the equipment connected to the system. Generally, the conventional protection overcurrent relay operates only after three to six cycles after the fault. To handle this higher fault current, system requires replacing the costly substation equipment or changing the system configuration by splitting the power system. The splitting of power system results decrease in operational flexibility and reduced reliability, so fault current limiters are an alternate way to reduce the fault current to a lower acceptable level [1].

Superconducting material that exhibit zero resistance at super conducting state and high resistance at normal conducting state, is an ideal element for a fault current limiter and their transition from superconducting state to the normal conducting state is expected to be very rapid. A superconductor operates in superconducting state until a fault current is detected. Superconducting fault current limiter utilizes the property of superconducting materials and provides instantaneous fault current reduction. It is a lengthy 
superconductor wire inserted in series with a transmission line or distribution feeder to limit peak value of fault current by abruptly increasing resistance [2]. Normal operation of SFCL does not produce any loss as well as voltage drop. During fault condition SFCL imparts certain amount of resistance to the system within a few milliseconds, which results the reduction of peak value of fault currents to levels acceptable to circuit breakers [3].

In power system context, self-healing covers the following areas: the rapid identification of major as well as minor problems in power system, mitigating any incompatible effects from casualties and fast recovery of the system from its faulty state to stable operating state [4]. The two main stages of the self-healing include the emergency reaction stage and restorative stage. If a fault has been occurred, first stage detects the fault and then reduces the fault by isolating the fault portion. These emergency reactions are automatic or predetermined, however it brings the system to a safer or less hazardous operating state. Once the system recovers from the initial emergency, then the restoration operation will starts [5]. In restoration operation, a series of reconfiguration process involves breaker manipulations like generation start up or shut down. These operations change the systems operational position for improving the overall system conditions. Compared to emergency reaction stage, the restoration stage is longer as well as more complicated and requires more complex solutions. The quantity of components that remain energized is the measure of self-healing performance [6].

Until now, there have been several research activities which discusses the fault current issues of smart grid and super-conducting fault current limiters for smart grid applications $[7,8]$. However the application of superconducting fault current limiters with multi agent system into a micro grid not found yet. The solution for increased fault current in micro grid by multi agent based SFCL technology is the main concern of this work. The multi agent system is selected here for the implementation of SFCL, it is not possible to use SFCL continuously in the circuit technically as well as economically [9]. In this paper, performance of multi agent based SFCL and its effects on system have been studied by considering typical smart grid model including generation, transmission and distribution network with dispersed energy resource.

The multi agent system is used to detect the abnormalities in the power system (i.e. fault) and sends the control signal to the circuit breaker which reduces the peakvalue of fault current by utilizing superconducting fault current limiter. Agents are being deployed in the system and they detect faults using centralized multi agent planning as shown in Fig. 1. In centralized multi-agent planning [10] scheme, a coordinator agent makes plans for individual agent and then identifies possible inconsistencies and conflicting interactions, like conflicts between agents over limited resources. The coordinator agent attempts to modify planning of each agent. The coordinator agent also combines the individuals planning into a multi-agent planning.

This paper is further structured as follows: Sections "Modeling of Wind Farm" and "Modeling of Resistive SFCL" defines modeling of wind farm and details the modeling of SFCL respectively. Section "Multi-Agent System (MAS)" describes a multi agent system, advantages of a multi agent system, multi agent system design, agent platform and proposed multi agent system for the smart grid. Section "Simulation Setup" presents the power system model developed in Matlab including generation, transmission and distribution with wind farm as the dispersed energy resource. Section "Result and Discussion" describes the

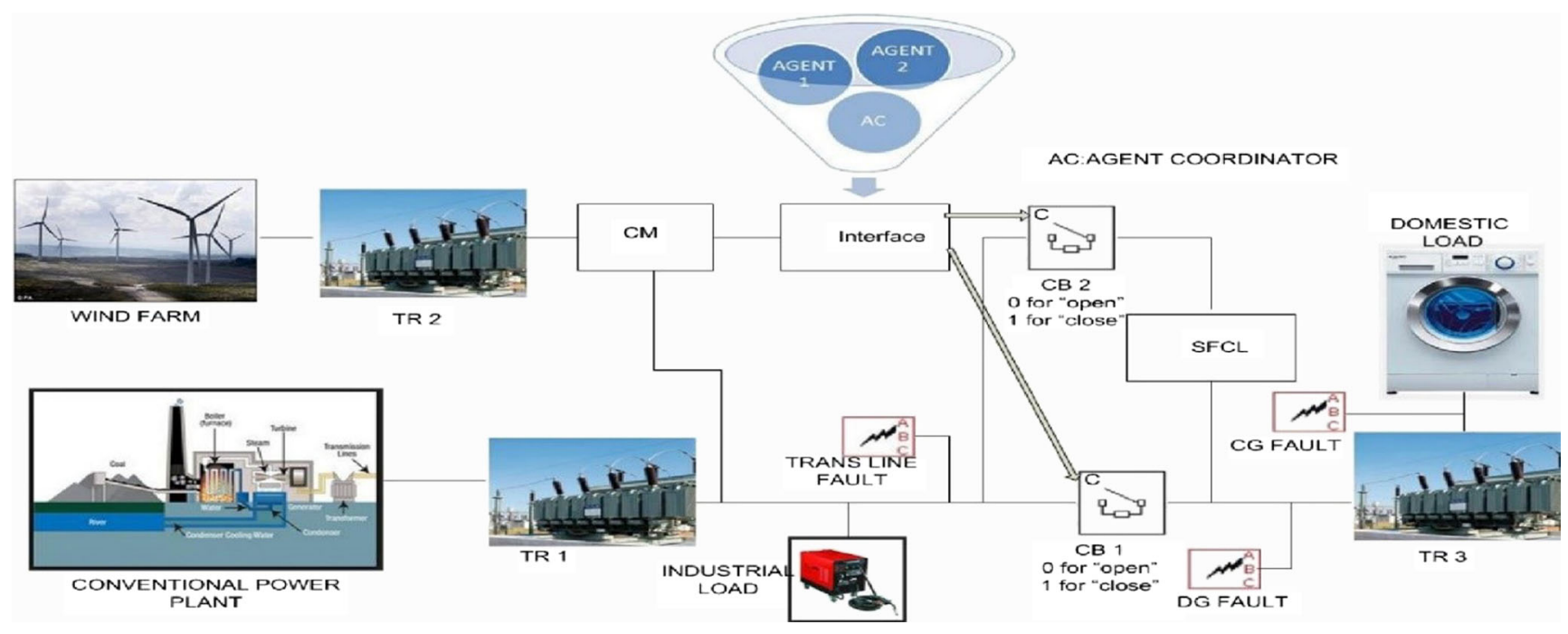

Fig. 1 Single line diagram of Power system model designed in Simulink/Sim Power System and interfacing with Agent system 
feasibility study, results and discussion after the successful implementation of the proposed multi agent system for different faults in the power system. Finally concludes that a centralized multi agent system with SFCL can give a self-healing power system.

\section{Modeling of Wind Farm}

Doubly-Fed Induction Generators (DFIGs) are one of the common types of generators used to produce electricity from wind turbines. DFIG can supply power at constant voltage and frequency with variable rotor speed [11]. The power developed by equivalent DFIG model is the sum of individual powers that developed by identical wind turbines [12].The DFIG wind farm model for the generation system consists of wind speed modules, turbine, drive train and generation system [13].

\section{Wind Speed Model}

The wind speed $\left(V_{w}\right)$ is modeled by combining base wind speed $\left(V_{b}\right)$, gust wind speed $\left(V_{g}\right)$, ramp wind speed $\left(V_{r}\right)$, and noise wind speed $\left(V_{n}\right)$ [14]. The wind speed model for a single wind turbine is given by Eq. 1 .

$V_{w}=V_{b}+V_{g}+V_{r}+V_{n}$

The equivalent wind speed model of the wind farm is the sum of wind speeds of individual wind turbines i.e.

$V_{w t}=V_{w 1}+V_{w 2}+V_{w 3}+\ldots \ldots \ldots \ldots .+V_{w n}$

for $\mathrm{n}$ individual wind turbines

\section{Wind Turbine Model}

For an area of the rotor disk (A), air density $(\rho)$, wind speed $(\mathrm{Vm})$ and power coefficient $(\mathrm{Cp})$, the mechanical power extracted from the wind is expressed by the Eq. 3 .

$P_{w}=\frac{1}{2} \rho V_{w}^{3} C_{p}$

The function dependence on both the tip speed ratio and the pitch angle of the rotor blades gives the characteristics of rotor aerodynamics. The ratio between the blade tip speed and the wind speed is called tip speed ratio [15].

\section{Drive Train System}

For the mechanical torque from the wind turbine rotor shaft $\left(T_{w t}\right)$, mechanical torque from the generator shaft $\left(T_{m e c h}\right)$, generator electrical torque $\left(T_{e}\right)$, stiffness $\left(K_{\text {mech }}\right)$, damping of mechanical coupling $\left(D_{\text {mech }}\right)[16]$, the drive train model of the turbine is given in Eqs. 4-6.

$$
\begin{aligned}
& T_{w}-T_{\text {mech }}=2 H_{r} \frac{\mathrm{d} \omega_{r}}{\mathrm{~d} t} \\
& T_{\text {mech }}=D_{\text {mech }}\left(\omega_{r}-\omega_{g}\right)+K_{\text {mech }} \int\left(\omega_{r}-\omega_{g}\right) d t \\
& T_{\text {mech }}-T_{e}=2 H_{g} \frac{\mathrm{d} \omega_{g}}{\mathrm{~d} t}
\end{aligned}
$$

\section{Generation and Control System}

In general, the power converters associated with doubly fed induction generator comprise the basic components of a wind power plant. The induction generator which is rotor wound is modelled using a third order model $[17,18]$. This model considers a reference frame with both the axis (direct and quadrature) and rotating at synchronous speed with stators fields peak flux aligned to the direct axis position. The active and reactive powers are controlled in a decoupled fashion by a bidirectional power converter connected to the rotor winding through a DC bus.

The wind turbine is controlled by rotor side converter. At wind speeds below the rated speed, wind turbine is driven for maximization of power efficiency and during wind speeds beyond the rated speed the power of wind turbine is limited to rated power using the drive control through converter. Apart from wind turbine speed control, both active and reactive powers are also regulated with respect to reference values as demanded by power regulation. The exchange of power to the grid (operating at unity power factor) from rotor circuit and voltage control is handled by supply side converter. The active power from DFIG wind turbine is delivered across the stator winding to the grid. The power exchange between converter and grid is used to derive the current source components which are namely direct and quadrature axis [19].

\section{Modeling of Resistive SFCL}

Critical temperature $\left(T_{c}\right)$, critical magnetic field $\left(H_{c}\right)$ and critical current density $\left(J_{c}\right)$ are the three important factors which define the superconducting state. These parameters depend on each other and material. To maintain super conducting state, all these three parameters should be below their critical value. During fault at least one of these three critical parameter immediately reaches to its critical value and superconducting property get vanished, leading to reduction in current [20,21].

A resistive SFCL has a simple structure without any iron core. Resistive SFCL is a lengthy superconductor wire inserted in series with a transmission line or distribution 
Table 1 Characteristic table of SFCL

\begin{tabular}{lll}
\hline Symbol & Quantity & Value \\
\hline$T_{c}$ & Critical temperature & $107^{0} \mathrm{~K}$ \\
$T_{0}$ & Temperature & $77^{0} \mathrm{~K}$ \\
$I_{c 0}$ & Critical current in T=Tc & $200 \mathrm{~A}$ \\
$R_{s h}$ & Shunt resistance & $50 \Omega$ \\
$C_{p}$ & Specific heat & $2 M \mathrm{Jm}^{-3} \mathrm{~K}^{-1}$ \\
$P$ & Cooling power & $1000 \mathrm{~kW}$ \\
$V_{S C}$ & Volume(flux flow) & $8 e^{-3} m^{3}$ \\
$A_{S C}$ & Cross section(flux flow) & $3 e^{-5} m^{2}$ \\
$\rho_{f}$ & flux flow resistivity & $1 e^{-10} \Omega m$ \\
\hline
\end{tabular}

feeder to limit peak value of fault current instantly by abruptly increasing the resistance and can also recover to its normal state after fault suppression without any external assistance. Thus, the limitation performance is the multisided interaction between the fault current, temperature, current depended on resistance, variable resistance of HTS substrate and other specification in the external power system[22]. The Table 1 shows the characteristic table of SFCL which is used for simulation [23].

We can represent the resistive SFCL (Rsfcl) as a function of different parameters given in Eq. 7.

$$
R_{s f c l}=\left\{\begin{array}{lr}
0 & \text { if } i_{s c} \leq I_{c}, T<T_{c} \\
\left\{\frac{J_{c 0}}{|J|}\left[\left(\frac{T-T_{b}}{T_{c}-T_{b}}-1\right)\right]+1\right\} *\left(\frac{\rho f J_{c 0}^{2} V_{s c}}{I_{i n i}{ }^{2}}\right) \\
\rho\left(\frac{T}{T_{c}}\right)\left(\frac{V_{a c}}{A_{s c}}\right) & \text { if } i_{s c}>I_{c}, T<T_{c}
\end{array}\right.
$$

For the design of superconducting fault current limiter three states are considered:
1. Superconducting state at temperature and current below a critical value.

2. Flux state at current above the critical value.

3. Normal conducting state at a temperature above the critical value. In flux state, the flux resistance depends on the HTS temperature $(\mathrm{T})$ and the instantaneous value of current density $(\mathrm{J})[23,24]$.

The Figs. 2 and 3 respectively show the variation of SFCL resistance and temperature in the flux flow state.

\section{Multi-Agent System (MAS)}

A Multi-Agent System (MAS) is the collection of several agents interacting with each other. A computational entity that operates without human intervention (Autonomous), interacts with each other (sociality), perceives and reacts to its environment (re-activity) and exhibits goal-oriented behavior by taking initiatives (pro-activity) is called an agent [25].

\section{MAS Design}

A lot of methodologies are available in the literature for designing a multi agent system [26-28] but their fundamentals remain the same. Specification and design of MAS have emerged by extending traditional software engineering and knowledge engineering approaches. The methodologies are based on the requirement and knowledge capturing of task, decomposition of a task, design of ontology followed by modeling of agent and their interaction. Generally, there are 3 phases in the design of a MAS viz conceptualization, analysis and design. The problem to be solved is specified in the conceptualization phase, analyzed in the analysis phase and the results of the analysis phase are used to produce the agent's communications strategy.

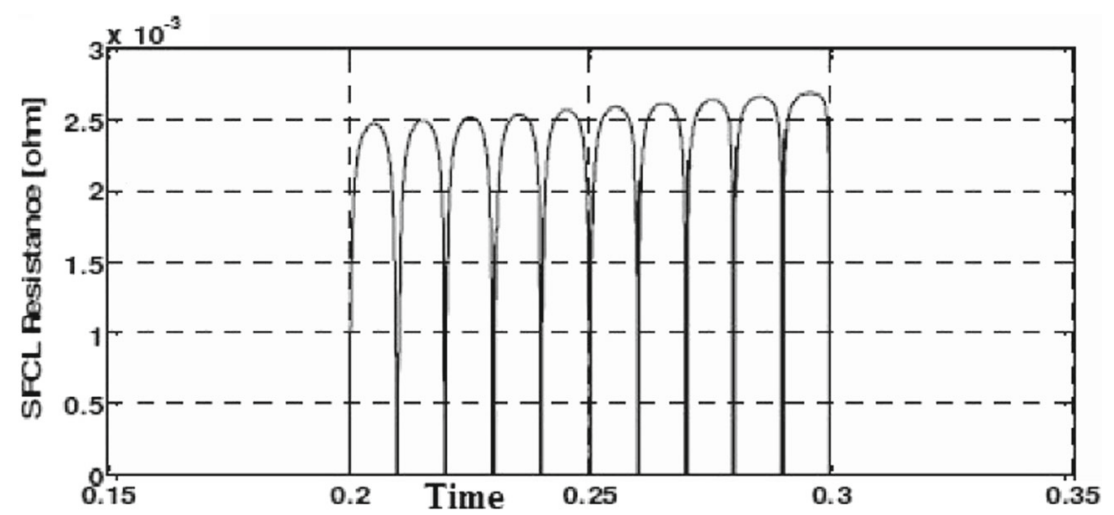

Fig. 2 Variation of SFCL resistance in flux flow state 


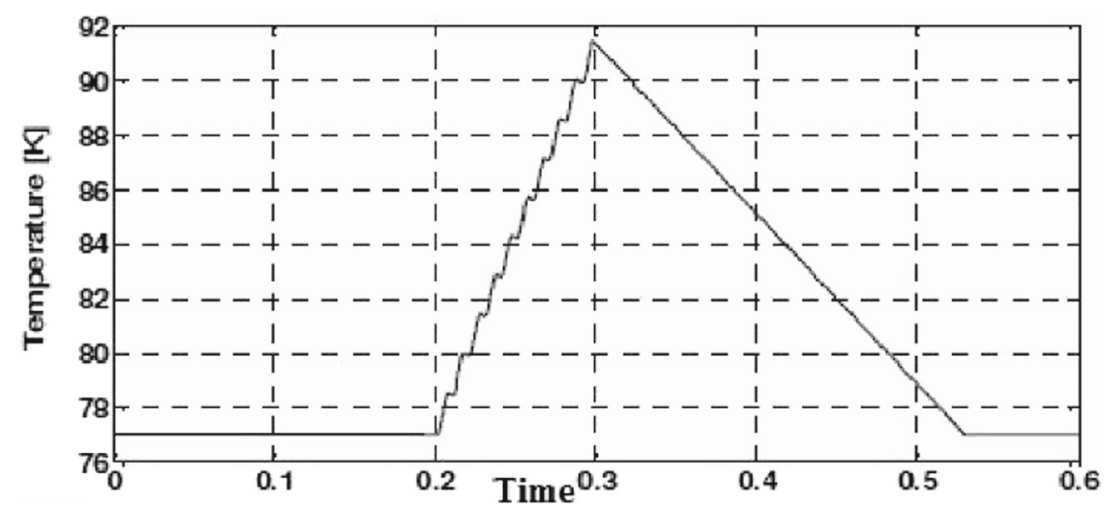

Fig. 3 Variation of SFCL temperature in flux flow state

In the design process, the output from each stage is used in the subsequent stages. This methodology begins with system requirement specification and capturing of knowledge to fulfill those requirements. During task decomposition stage, the specified requirement and captured knowledge are transformed in to a hierarchy of tasks and sub tasks. Next stage is designing the vocabulary of agent communication called ontology. Modeling of agent uses the task hierarchy and ontology to identify a group of autonomous agents with the abilities to carry out the tasks. The outcome of this stage is a set of agents and specific tasks that the agents should perform. After the agent modeling, the agent interaction must be determined.

\section{Agent Platform}

The Agent Management System (AMS) is the entity which exerts supervisory control over access to and use of the Agent Platform. The agent management system provides white-page and life-cycle services, maintaining a directory of agent identifiers (AID) and agent state. Each agent must register with an AMS in order to get a valid AID. The default yellow page is provided by an agent called Directory Facilitator (DFs).The software component controlling all the exchange of messages within the platform, including messages to/from remote platforms is called the message transport system.

\section{Proposed Multi Agent System}

This paper uses Java Agent Development Framework (JADE) software [29] for implementation of the MAS. JADE is a middleware that exchanges data between Simulink and Java agents. JADE assists the development of multi-agent systems in abidance with FIFA (Foundation for
Intelligent Physical Agent) [30]. JADE provides a collaborative environment to design multi-agent systems. Agents may be created on different platforms i.e. computers, but they have to register on a single central AMS (Agent Management System), which keeps track of all addresses. Similarly, all agents register their services to a single central DF (directory facilitator). DF maps service descriptions to agent identifiers and allows an agent to add/modify/delete information for them $[31,32]$.

Figure 4 shows the schematic diagram for implementation of the SFCL with MAS. As soon as the MAS starts, all agents register at AMS and DF agent. All agents share their information about network with agent coordinator. Agent Coordinator combines this shared information and accordingly detects the fault and sends out a control signal to the circuit breaker.

In JADE, the FIFA-ACL defines the library for communication. Every message has performance associated with it that defines the message communication act. We have used "Inform" type of messages in which the sender informs the receiver that given proposition is true. On the basis of intention, we have divided our messaging system in four categories.

1. Messages from Agent Coordinator: In a centralized system, agent coordinator takes partial plans of each coordinator and then merges their information to take a decision about the signal that is to be sent to the control box.

2. Messages by Agents: These messages are generated by all registered agents for AMS agent. Once, all agents get their relative information, they send back their decision to agent coordinator. These agents deliver their changes to other relevant agents with same registered service at DF as well. 


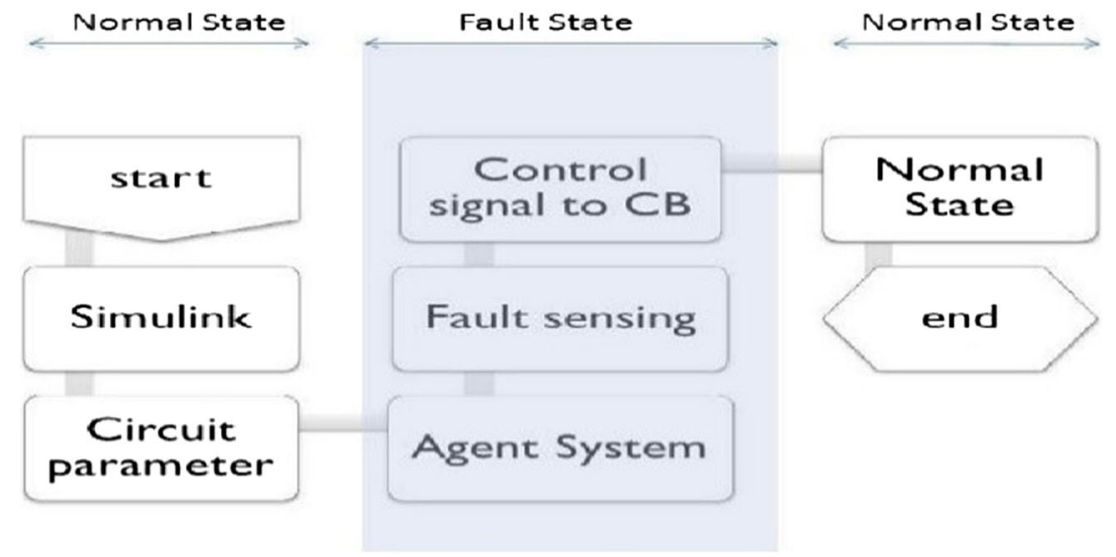

Fig. 4 Schematic diagram of SFCL with MAS

3. Data Amend Message: This message is aired by agents once they stop getting further information from Simulink.

4. Shutting Down: This message is sent by an agent coordinator to an agent once the requirement of that agent vanishes. After getting this message, agent deregisters themselves from JADE DF (directory facilitator). This deregistration needs to be done manually otherwise a copy of agents services would remain in the directory facilitator.

On the basis of agent behavior, we can classify agents in two categories. One is the central agent i.e. agent coordinator that takes cumulative action by summing up effect of each agent and the others are the peripheral agents which perform a partial task.

Sniffer Agent is a debugger tool of JADE that is used to document the conversation between agents as shown in Fig. 5. Firstly, Agent Coordinator (Simulink Agent) pass as information of the circuit to all other agents exists in the system. Agent 1 and Agent 2 communicate and send the circuit information i.e. current values back to agent coordinator which would further pass its decision signal to the circuit breaker.

\section{Simulation Setup}

Matlab/Simulink/ Sim-Power System is selected for the design and implementation of the SFCL model. A complete smart grid power network including generation, transmission and distribution with dispersed energy resources (Wind Farm) is also implemented in it. S-function in Matlab is utilized to interact with JADE. Simulink/ Sim-Power System has a number of advantages over its contemporary simulation software (like EMTP and PSPICE) due to its open architecture, a powerful graphical user interface and versatile analysis and graphics tools [33].

\section{Power System Model}

Figure 1 show the power system model which is designed and developed in Simulink/SimPowerSystem with multi agent integration. The power system model comprises a conventional 100MVA power plant composed of a 3-phase synchronous machine linked with a $200 \mathrm{~km}$ long $154 \mathrm{kV}$

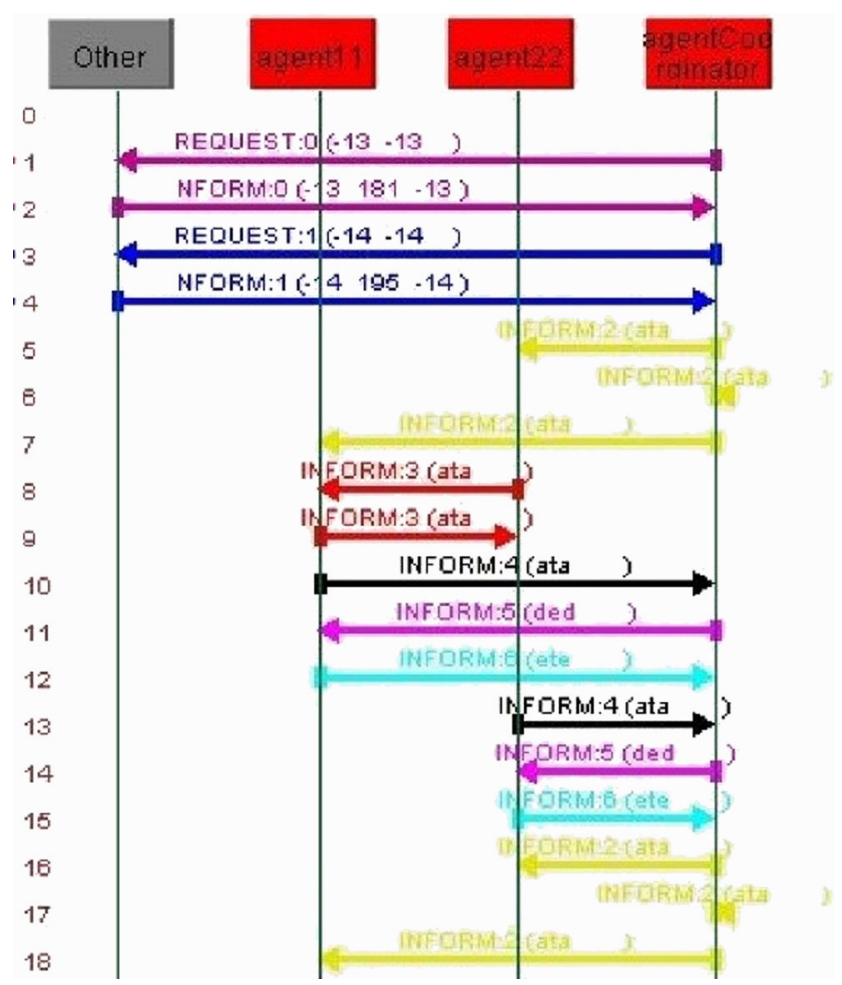

Fig. 5 Sniffer agent diagram of MAS 


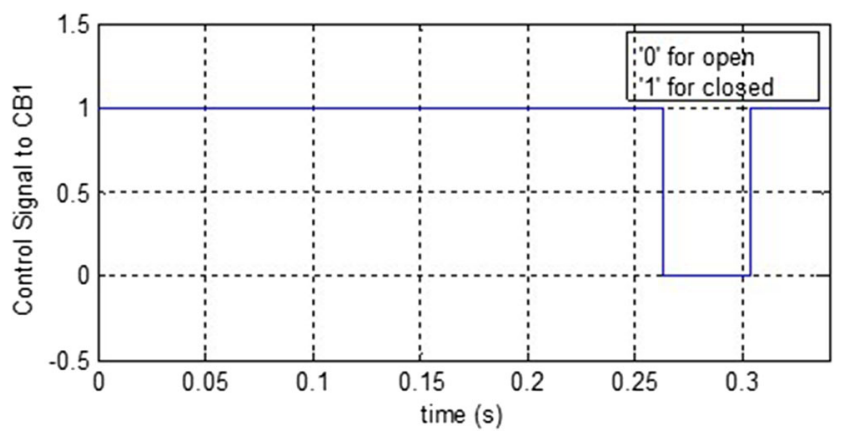

Fig. 6 Control signal Send by MAS to CB1

distributed-parameters transmission lines through a stepup transformer TR1. At the substation (TR3), voltage is stepped down from $154 \mathrm{kV}$ to $22.9 \mathrm{kV}$. Industrial load (6 MW) and domestic loads each of 1 MW are being supplied by distinct distribution networks. The dispersed energy resource (Wind Farm) is directly connected with the branch network through transformer TR2 and is providing power to the domestic loads.

Artificial faults at different locations and the locations of the SFCL are indicated in Fig. 1. The SFCL is located (in all the three phases) in such a way that under normal condition the circuit breaker (CB 1) is closed and circuit breaker (CB 2 ) is open and during fault condition the circuit breaker (CB 1) will open and circuit breaker (CB 2) will close by using proposed multi agent system. Three phase to ground faults are marked as distribution grid fault, transmission line fault and customer grid fault. In Fig. 1 S-function is controlled by the JADE agent and these S-function $[34,35]$ acts as an interface between JADE and Matlab-Simulink.

\section{Result and Discussion}

The performance of multi agent based SFCL is analyzed for three phase lines to ground fault at distribution grid, transmission line and customer grid as in shown in Fig. 1.Three phase fault has been simulated for a period of 0.26 seconds

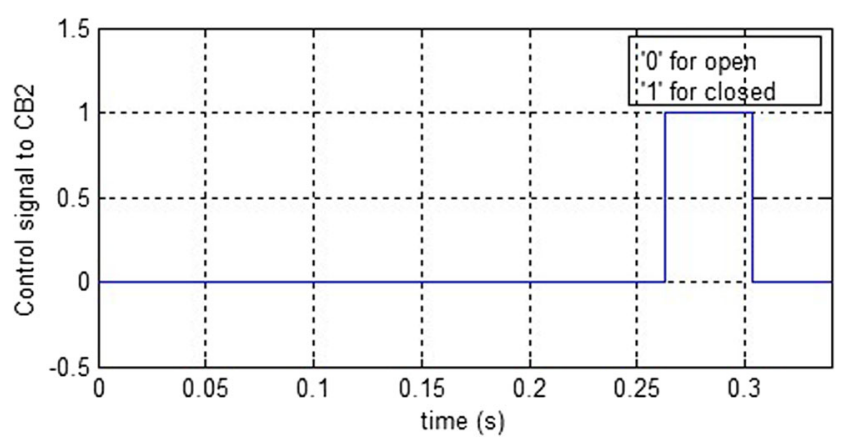

Fig. 7 Control signal Send by MAS to CB2

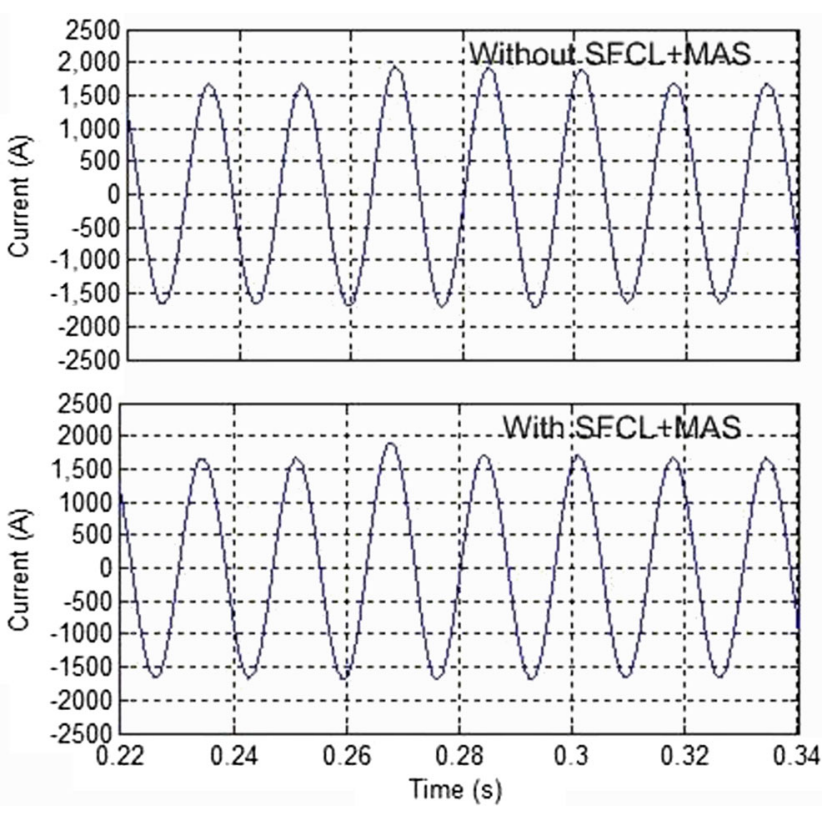

Fig. 8 Fault current from wind farm with and without SFCL in case of fault in distribution grid

to 0.30 seconds, that is the fault occurs at 0.26 second and cleared at 0.30 second.

During normal condition i.e. up to 0.26 seconds CB1 of the Fig. 1 is remain closed as the signal 1 send by MAS like in Fig. 6. and after 0.26 second fault occurs, at this instant

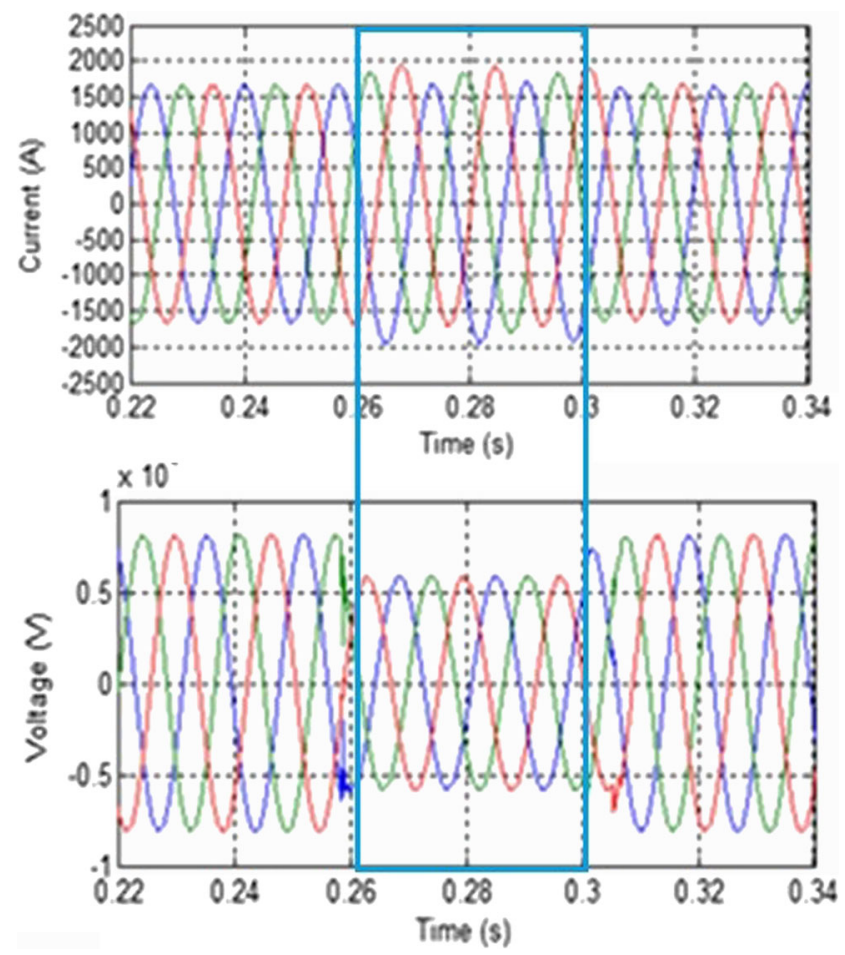

Fig. 9 Three phase Fault current and voltage from wind farm without SFCL in case of fault in distribution grid 


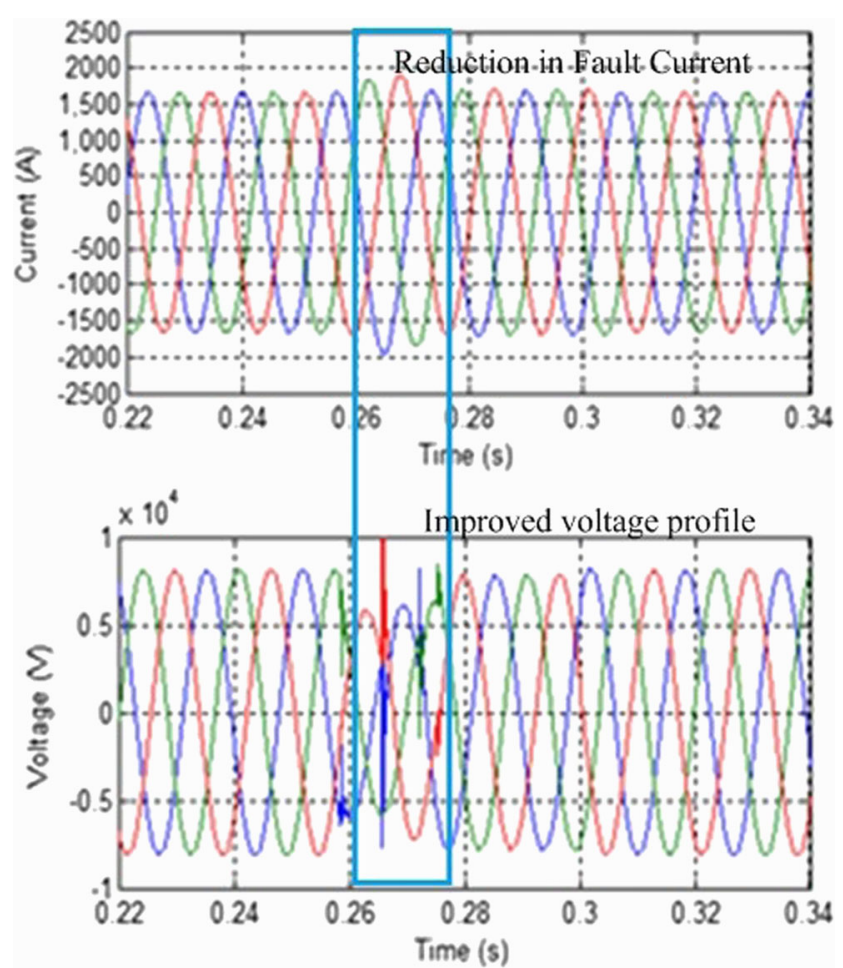

Fig. 10 Three phase Fault Current and voltage from wind farm with SFCL in case of fault in distribution grid

MAS send a signal 0 to $\mathrm{CB} 1$ to open $\mathrm{CB} 1$ as in Fig. 6 and at the same instant signal 1 to $\mathrm{CB} 2$ as in Fig. 7 to close and put SFCL in action as in Fig. 1. After 0.3 second faults get cleared and system comes to normal condition by sending control signals by MAS as in Figs. 6 and 7 to close CB1 and
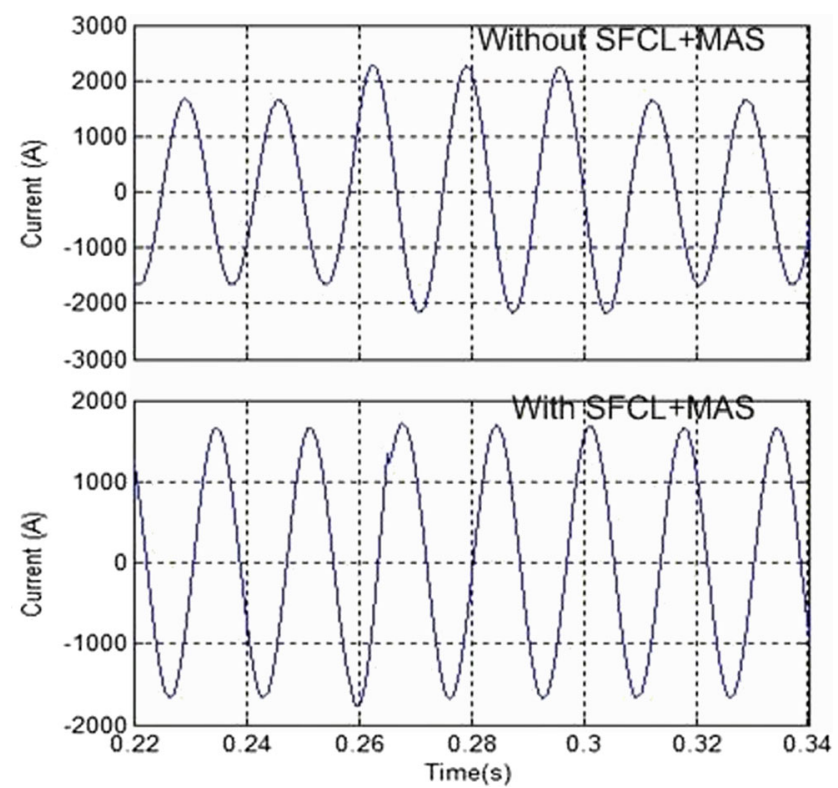

Fig. 11 Fault current from wind farm with and without SFCL in case of fault in transmission line open CB2 to remove super conducting fault current limiter from action.

\section{Distribution Grid Fault}

Distribution grid fault is comparatively a large fault as it occurred in the high voltage side of the distribution network. Figure 8 shows the fault current from the wind farm without and with the implementation of multi agent based SFCL respectively in case of fault in the distribution grid. Figure 8 shows that without the implementation of multi-agent system, peakvalue of fault current increases to $1985 \mathrm{~A}$ and with the successful implementation of MAS it is observed that there is reduction in the peakvalue of fault current from 1985A to 1634A. Under normal condition circuit breaker, CB 1 is closed and normal current flows through the entire power network. When a fault occurs in the power system, the fault current always flows towards fault point i.e. fault current starts flowing from the wind farm to the fault occurring point and damage the equipment connected to the system. In proposed MAS, agent 1 always monitors the system for detecting faulty condition.

The agents in proposed MAS has been selected in such a way that if agent 1 senses a fault it passes information to the agent 2 . The purpose of agent 2 is decision making and sending control signals back to agent 1 that is representing

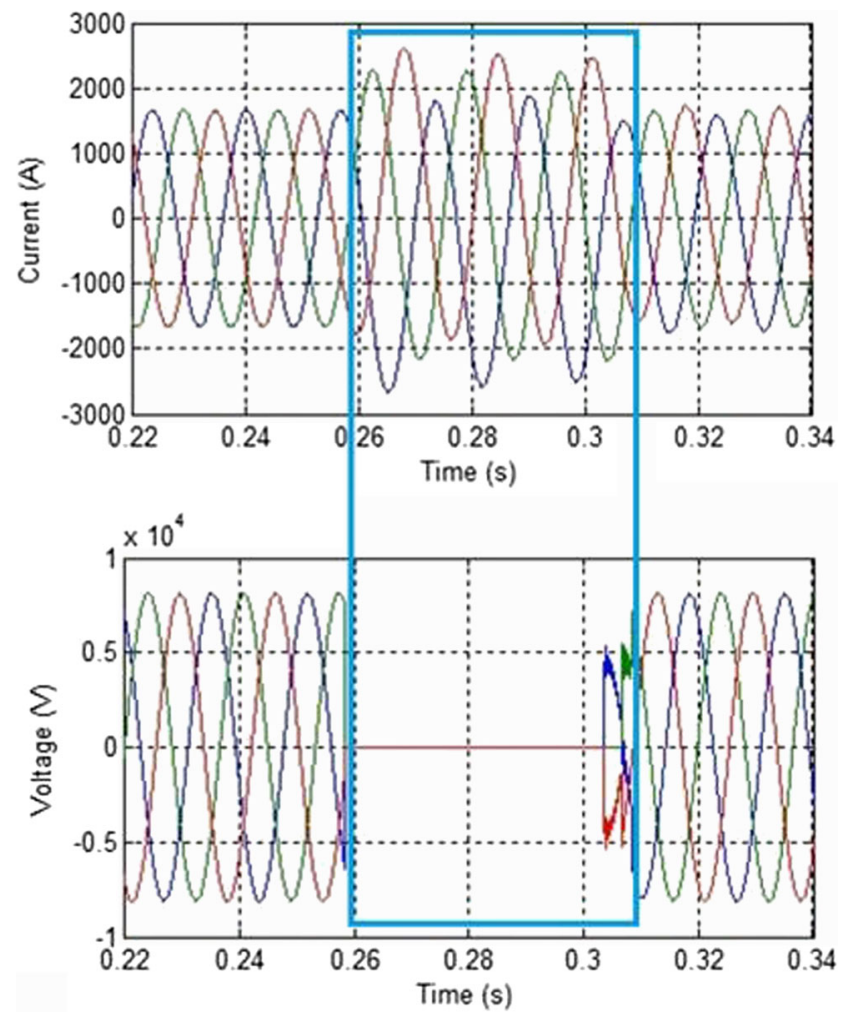

Fig. 12 Three phase Fault current and voltage from wind farm without SFCL in case of fault in Transmission line 


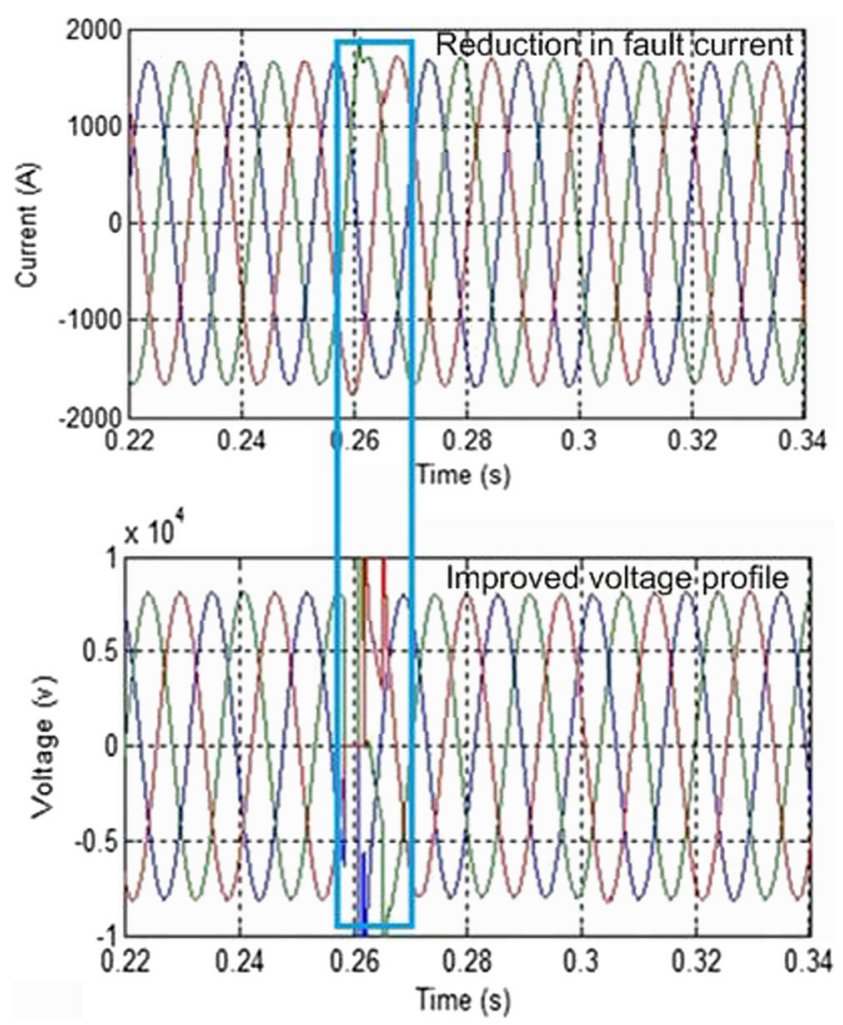

Fig. 13 Three phase Fault Current and voltage from wind farm with SFCL in case of fault in Transmission line

Simulink to reduce the peak value of fault current. During fault, agent 2 sends a control signal 0 to the $\mathrm{CB} 1$ and control signal 1 to $\mathrm{CB} 2$.By getting the respective control signals to the circuit breakers, the CB 1 opens and CB2 is closed and hence SFCL action comes in to the picture. Now the entire
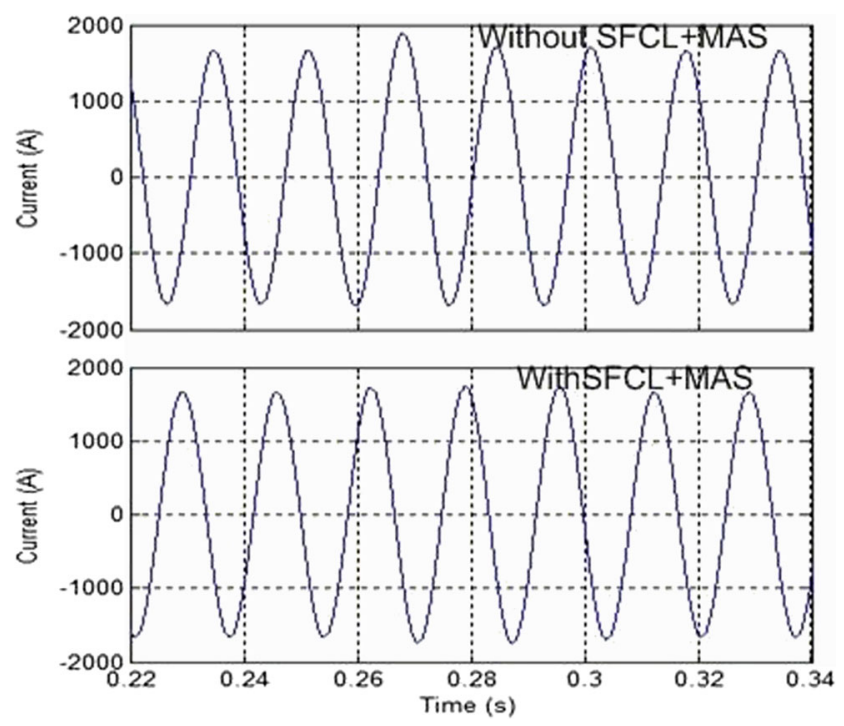

Fig. 14 Fault current from wind farm with and without SFCL in case of fault in customer grid fault current is flowing through the SFCL so the successful reduction in peak value of fault current is observed in Fig. 8.

Figures 9 and 10 shows the three phase current and voltage from the wind farm without and with the implementation of multi agent based SFCL in case of fault in the distribution grid. From Figs. 9 and 10, it is observed that there is a successful improvement in voltage profile and peak value of fault current reduction as marked in Fig. 10 with the effect of multi agent based SFCL. The artificial distribution grid fault has been created for time 0.26 to 0.3 i.e. for 0.04 seconds as shown in Fig. 9.In Fig. 10, peakvalue of fault current reductions and voltage profile improvement are observed in less than 0.01 seconds peakvalue of fault current with the inclusion of fault detection time 0.0025 second. i.e. at time 0.27 . The advantage of SFCLs with multi agent system includes automatic over current sensing, automatic recovery and faster over current limiting operations that are supposed to be the unique countermeasures to solve the drawbacks. These draw-backs could not be overcome by the conventionally developed fault current limiter.

\section{Transmission Line Fault}

Transmission line fault rarely occurs which results in a very high intensity fault current. Figure 11 shows the fault

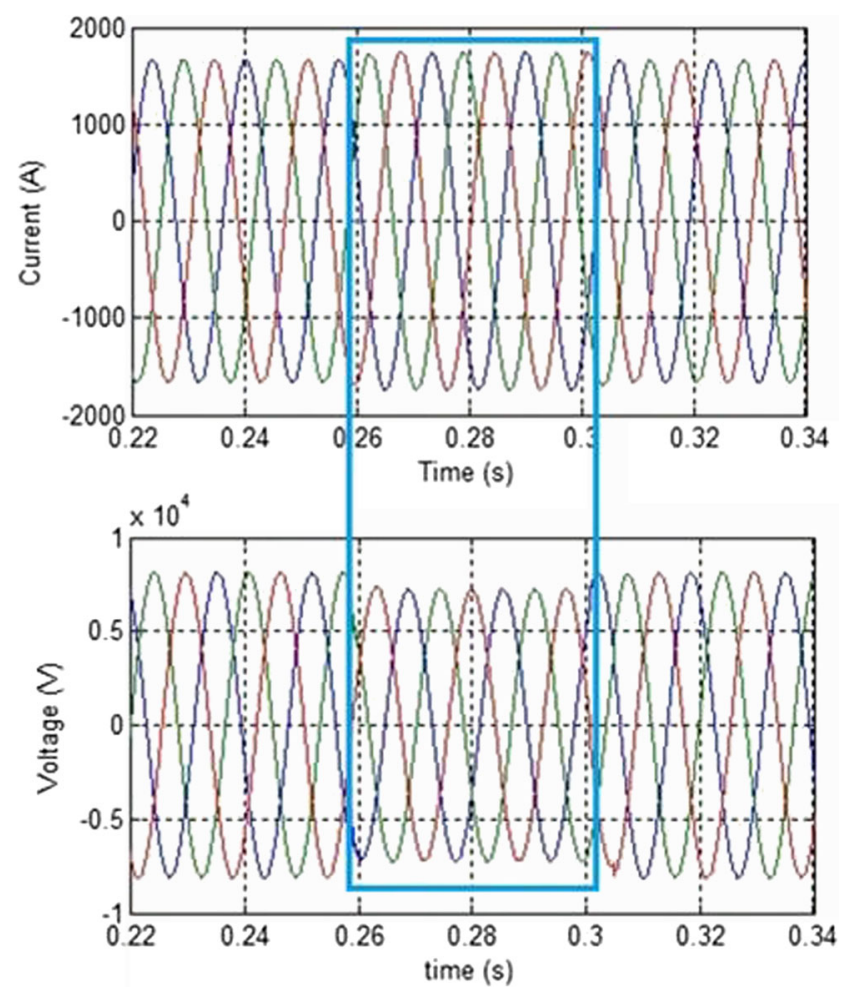

Fig. 15 Fault current from wind farm without SFCL in case of fault in customer grid 


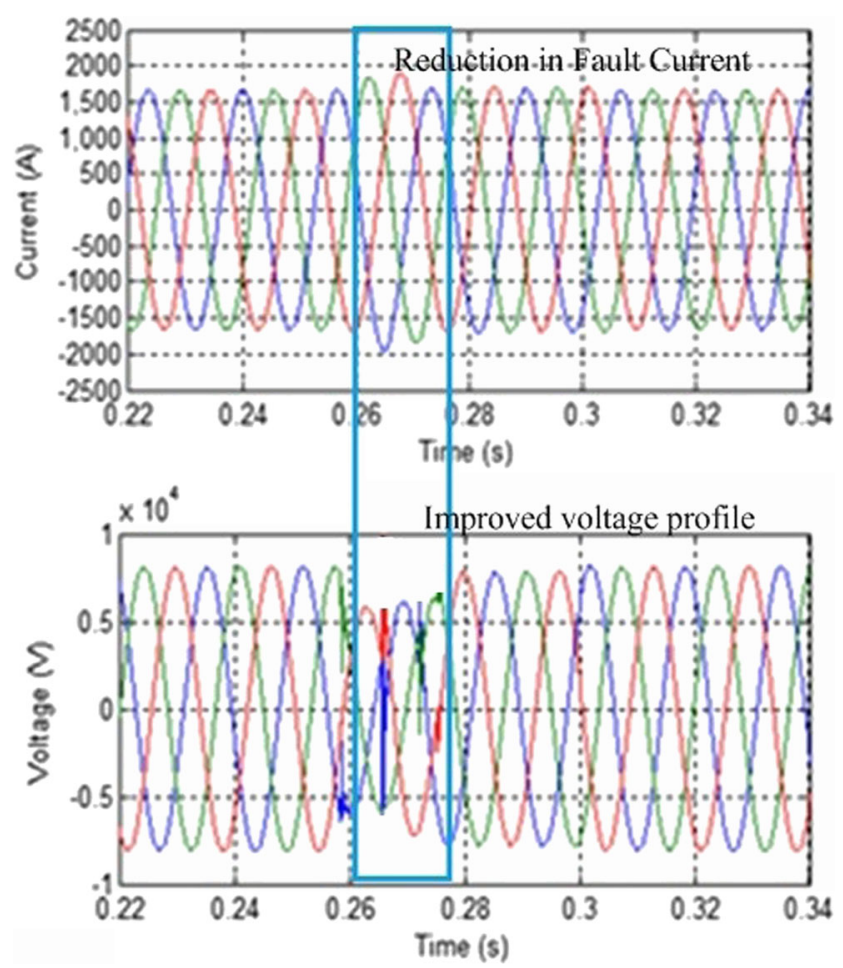

Fig. 16 Three phase Fault current and voltage from wind farm with SFCL in case of fault in Customer Grid

current from the wind farm without and with the implementation of multi agent based SFCL respectively in case of fault in the transmission line. In Fig. 11, without the implementation of multi-agent system the peak value of fault current increases to $2240 \mathrm{~A}$ and with the successful implementation of MAS it is observed that there is a complete reduction in peak value of fault current. Also current profile is improved with a peek of 1670A. In this case also agent 1 monitors the system for detecting faulty condition or note by sensing the current in the power network. Once a fault is detected by the agent 1 , the proposed multi- agent SFCL system works as explained in section "Distribution Grid Fault" and put SFCL in action and reduce the peak value of fault current. The artificial transmission line fault has been created for the time 0.26 to 0.3 i.e. for $0.04 \mathrm{sec}-$ onds but the fault is persisting for some time more (up to 0.31 ) as shown in Fig. 12 because the transmission line fault has been created near the wind farm. In Fig. 13, peak value of fault current reductions and voltage profile improvement are observed in less than 0.01 seconds i.e. at time 0.27.

Figures 12 and 13 shows the three phase current and voltage from the wind farm without and with the implementation of multi agent based SFCL respectively in case of fault in transmission line. From Figs. 12 and 13, it is observed that there is a successful and almost complete improvement of voltage profile and peak value of fault current reduction as marked in Fig. 13 with the effect of multi agent based SFCL. Furthermore, SFCLs with proposed multi agent system can be used to recover some restriction such as voltage sag and stable improvement of the system.

\section{Customer Grid Fault}

In Fig. 14, without the implementation of multi-agent system the peak value of fault current increases to $1687 \mathrm{~A}$ and with the successful implementation of MAS it is observed that there is a complete reduction in peak value of fault current to $1589 \mathrm{~A}$ after first fault current cycle. The SFCL system works as explained in section "Distribution Grid Fault" and puts SFCL in action. Now the entire fault current is flowing through the SFCL which reduces the peak value of fault current. The artificial customer grid fault has been created for time 0.26 to 0.3 i.e. for $0.04 \mathrm{sec}-$ onds as shown in Fig. 15. Peak value of fault current reduction and voltage profile improvement are observed in less than 0.01 seconds i.e at time 0.27 as shown in Fig. 16 after successful the implementation of multi agent based SFCL. The SFCLs essentially use the properties of the superconducting material affected by the presence of an excessive current by having an increase in resistance. This limitation of the current beyond the predetermined value can be achieved in all the cases. From the results shown in above sections, SFCL can reduce the VoltAmpere rating by limiting the excessive current in the event of a fault and improve the transient stability of the system.

\section{Conclusion}

For emerging smart grids, the attribution of self-healing is very important. In this paper, multi agent framework with superconducting fault current limiter has been discussed, which facilitate self-healing for a power system. Several recent self-healing approaches have been included in this discussion. Agent protocols have been developed and simulated a micro grid Multi Agent System. The simulation results demonstrates performance during a casualty requiring self-healing and the same has been implemented. The power system self-healing is difficult, here the case is made for combining multi-agent control with superconducting fault current limiter to this end. By considering three phase to ground faults at different locations, a feasible analysis has been done with the help of proposed multi agent system based SFCL. From the analysis it is observed that successful 
Table 2 Effect of MAS based SFCL for different types of fault

\begin{tabular}{lllllll}
\hline Diffrent types of fault & $\begin{array}{l}\text { Current without } \\
\text { SFCL(A) }\end{array}$ & $\begin{array}{l}\text { Current with } \\
\text { SFCL(A) }\end{array}$ & $\begin{array}{l}\text { Voltage without } \\
\text { SFCL(kV) }\end{array}$ & $\begin{array}{l}\text { Voltage with } \\
\text { SFCL(kV) }\end{array}$ & $\begin{array}{l}\text { No: Cycles to compensate } \\
\text { without SFCL }\end{array}$ & $\begin{array}{l}\text { No: Cycles to } \\
\text { compensate with SFCL }\end{array}$ \\
\hline Distribution grid fault & 1985 & 1634 & 5.5 & 7.7 & 3 & 1 \\
Transmission line fault & 2240 & 1670 & 0 & 7.7 & 3 & 1 \\
Customer grid fault & 1687 & 1589 & 6.4 & 7.7 & 3 & 1 \\
\hline
\end{tabular}

reduction in peak value of fault current and improvement of voltage profile is achieved for all types of fault in the power system and is given in Table 2 . The simulation results are included to validate this analysis and also to show that the proposed multi-agent based SFCL system takes $0.01 \mathrm{sec}-$ ond to self-heal the system after occurring outage. Thus the above said system is feasible for all types of faults in the power system. Future work of this study will include the improvement of efficacy in data processing step like missing values from any agent?. Several methods like Mean or mode substitution, Regression substitution, Hot deck imputation and KNN imputation have been purposed.

Acknowledgements The authors gratefully acknowledges the support of Department of Electronics and Information Technolog for funding this project sponsored by MoCIT and monitored by Media Lab Asia.

\section{References}

1. Lin Y, Majoros M, Coombs T, Campbell AM (2007) System studies of the superconducting fault current limiter in electrical distribution grids. Proc IEEE Trans Appl Supercond 17(2):23392342

2. Sousa de, Batista WT (2015) Transient Simulations of Superconducting Fault Current Limiters. PhD diss., Universidade Federal do Rio de Janeiro

3. Lin Y, Lin LZ, Juengst K-P. (2002) Application studies of superconducting fault current limiters in electric power systems. Proc IEEE Trans Appl Supercond 12(1):900-903

4. Amin M, Wollenberg BF (2005) Toward a smart grid: power delivery for the 21st century. Proc IEEE Power Energ Mag 3(5):3441

5. Moslehi K, Kumar R (2006) Vision for a self-healing power grid. ABB Review 4

6. Colson CM, Nehrir MH, Gunderson RW (2011) Distributed multiagent microgrids: a decentralized approach to resilient power system self-healing. Proc IEEE 4th International Symposium on Resilient Control Systems (ISRCS):83-88

7. Driesen J, Vermeyen P, Belmans R (2007) Protection issues in micro-grids with multiple distributed generation units. Proc Power Conversion Conference Nagoya:646-653

8. Friedl W, Fickert L, Schmautzer E, Obkircher C (2008), Safety and reliability for smart micro and islanded grids. Presented at the CIRED Seminar Smart Grids for Distribution
9. Khan UA, Seong JK, Lee SH, Lim SH, Lee BW (2011) Feasibility analysis of the positioning of superconducting fault current limiters for the smart grid application using simulink and simpowersystem. Proc IEEE Trans Appl Supercond 21(3):21652169

10. Bellifemine F, Caire G (2004) Dominic greenwood Multi-agent system with JADE. John wiley and Son, Ltd

11. Pena R, Clare JC, Asher GM (1996) A doubly fed induction generator using back-to-back PWM converters supplying an isolated load from a variable speed wind turbine. Proc Electr Power Appl 143(5):380-387

12. Garcia CA, Fernndez LM, Jurado F (2015) Evaluating reduced models of aggregated different doubly fed induction generator wind turbines for transient stabilities studies. Wind Energy 18(1):133-152

13. Sujil A, Rajesh K (2014) Feasible positioning of super conducting fault current limiters for wind farm intermittency and fault current reduction in a smart power system. Proc WSEAS Trans Power Syst 9:16-23

14. Anderson PM, Bose A (1983) Stability simulation of wind turbine system. Proc IEEE Trans PAS:3791-3795

15. Heier S (1998) Grid integration of wind energy conversion systems. Chicester: John Wiley and Sons

16. Fernandez LM et al. (2008) Equivalent models of wind farms by using Aggregated wind turbines and equivalent winds. Proc Energy Convers Manag 50(3):691-704

17. Muller SD, Doncker RIKWD (2002) Doubly fed induction generator systems for wind turbines. Proc IEEE Industrial Applications Magazine

18. Ekanayake JB, Holdsworth L, Jenkins N (2003) Comparison of 5 th order and 3rd order machine models for doubly fed induction generator (DFIG) wind turbines. Proc Electr Power Syst Res 67(3):207-215

19. Fernandez LM et al. (2008) Aggregated dynamic model for wind farms with doubly fed induction generator wind turbine. Renew Energy 33(1):129-140

20. Ye L, Majoros M, Coombs T, Campbell AM (2007) System studies of the superconducting fault current limiter in electrical distribution grids. Proc IEEE Trans Appl Supercond 17(2):23392342

21. Moghadasi AH, Heydari H, Salehifar M (2010) Reduction in VA rating of the unified power quality conditioner with superconducting fault current limiters. Proc IEEE Conference Power Electronics and Drive Systems and Technologies :382-387

22. Sugimoto S, Kida J, Arita H, Fakui C, Yamagiwa T (1996) Principle and characteristics of a fault current limiter with series compensation. Proc IEEE Trans Power Delivery 11(2):842847

23. Heydari H, Moghadasi AH (2011) Optimization Scheme in Combinatorial UPQC and SFCL Using Normalized Simulated Annealing. Proc IEEE Trans Power Delivery 26(3):1489-1498 
24. Shimizu H, Yokomizu Y (2003) A study on required volume of superconducting element for flux flow resistance type fault current limiter. proc IEEE Trans Appl Supercond 13(2):2052-2055

25. Pipattanasomporn M, Feroze H, Rahman S (2009) Multi-agent systems in a distributed smart grid: Design and implementation Proc IEEE/PES Power Systems Conference and Exposition: 1 -8

26. Brazier FMT, Dunin-Keplicz BM, Jennings NR, Treur J (1997) DESIRE: Modelling multi-agent systems in a compositional formal framework. Int J Cooperative Inf Syst 6(1):67-94

27. Inglesia CA, Garijo M, Gonzalez JC, Velasco JR (1998) Analysis and design of multi-agent systems using MAS-CommonKAD. In: Intelligent Agents IV: Agent Theories, Architectures and Language: $313-326$

28. Schrieber G, Akkermans H, Anjewierden A, de Hoog R, Shadbolt N, van der Velde W, Wielinga B (1999) Knowledge Engineering and Management: The Common KADS Methodology Cambridge, MA: The MIT, Press

29. http://jade.tilab.com/, accessed January 2013

30. Caire G (2003) JADE Programming for Beginners. TI Lab S. p. A, http://jade.cselt.it/

31. Sujil A, Agarwal SK, Kumar R (2014) Centralized multi-agent implementation for securing critical loads in PV based microgrid. J Mod Power Syst Clean Energy 2(1):77-86

32. Sujil A, Agrwal SK, Kumar R (2013) Centralized multi-agent self-healing power system with super conducting fault current limiter. Proc IEEE Conference on Information and Communication Technologies (ICT), Thuckalay,Tamil Nadu, India:1182-1187

33. Dessaint L, Al-Haddad K, Le-Huy H, Sybille G, Brunelle P (1999) A power system tool based on Simulink. Proc IEEE Trans Ind Electron 46(6): 1252-1254

34. Mendham P, Clark T (2005) MACSim: A Simulink Enabled Environment for Multi Agent System Simulation, 16th IFAC World Congress, Prague

35. Robinson CR, Mendham P, Clarke T (2010) MACSimJX: A Tool for Enabling Agent Modeling with Simulink Using JADE. Proc J Physical Agents 4(3)
Sujil A was born on May 23, 1989 received the B.Tech. degree (with first class honors) in Electrical Engineering from the Govt Engineering College Idukki, India in 2011 and M.Tech. degree in Electrical Engineering from the Malaviya National Institute of Technology (MNIT), Jaipur, India from 2011-2013. currently he is pursuing $\mathrm{Ph} . \mathrm{D}$. in electrical engineering in Malaviya National Institute of Technology, Jaipur, India. His research interests includes power systems, smart grid applications, multi agent system and demand side management.

Saurabh Kumar Agarwal received the B.Tech. degree (with first class honors) in Electrical Engineering from Malaviya National Institute of Technology, Jaipur, India. His research interests are Application of Artificial Intelligence and nature based algorithm in various scientific problems.

Rajesh Kumar received the B. Tech. degree (with first class honors) in electrical engineering from National Institute of Technology (NIT), Kurukshetra, India in 1994, the M. E. from Malaviya National Institute of Technology (MNIT), Jaipur, India in 1997 and the Ph.D. degree in Intelligent systems from University of Rajasthan, India in 2005. Since 1995, he has been a Faculty Member in the Department of Electrical Engineering, MNIT, Jaipur, where he is currently an Associate Professor. He was Post Doctorate Research Fellow in the Department of Electrical and Computer Engineering at the National University of Singapore (NUS), Singapore, from 2009 to 2011. He has published over 250 refereed journals and international conference proceeding papers. His field of interest includes theory and practice of intelligent systems, computational intelligence and applications to power system, electrical machines, power electronics and drives. Dr. Kumar was a recipient of Career Award for Young Teachers in 2002 from Government of India. $\mathrm{He}$ is a Senior Member IEEE, Member IE (INDIA), Fellow Member IETE, Member CSI and Life Member ISTE. 